DOI: $10.15593 / 2224-9982 / 2019.56 .09$

УДК 620.178 .3

\author{
М.А. Артамонов ${ }^{1}$, Д.В. Немцев ${ }^{1}$, В.Э. Меденцов ${ }^{2}$, В.С. Соловьев ${ }^{2}$ \\ ${ }^{1}$ Опытно-конструкторское бюро им. А. Люльки - филиал ПАО «ОДК-УМПО», Москва, Россия \\ ${ }^{2}$ Лыткаринский машиностроительный завод - филиал ПАО «ОДК-УМПО», Москва, Россия

\section{ИССЛЕДОВАНИЕ ИСПЫТАННЫХ НА МАЛОЦИКЛОВУЮ УСТАЛОСТЬ ЦИЛИНДРИЧЕСКИХ ОБРАЗЦОВ ИЗ НИКЕЛЕВОГО СПЛАВА ЭП741НП ДЛЯ ОПРЕДЕЛЕНИЯ ПАРАМЕТРОВ ПЕРИСА И ПЕРИОДА ЗАРОЖДЕНИЯ ТРЕЩИНЫ}

\begin{abstract}
При помощи растровой электронной микроскопии была получена информация о зарождении и кинетике развития усталостных трещин в материале из гранулированного никелевого сплава ЭП741НП. Данный сплав используется для изготовления дисков горячей части газотурбинных двигателей. Проводилось исследование изломов цилиндрических образцов, испытанных на малоцикловую усталость в широком диапазоне значений температуры (от 20 до $750{ }^{\circ} \mathrm{C}$ ) и в условиях жесткого цикла нагружения (фиксированный размах деформации). Результаты фрактографического анализа позволили определить место зарождения усталостной трещины, живучесть (длительность роста трещины) и период зарождения для разных значений температуры. Выявлена зависимость периода зарождения трещины от температуры. При температуре до $450^{\circ} \mathrm{C}$ удельная доля периода зарождения трещины в общей долговечности образца практически не изменяется и занимает более 50 \%. Для каждого испытанного образца были определены форма и размеры трещины, которые в дальнейшем использовались для математического конечно-элементного моделирования с целью определения коэффициентов интенсивности напряжений. На основе фрактографического анализа и конечно-элементного моделирования были определены параметры Периса, характеризующие кинетику устойчивого периода роста трещины. Полученные значения параметра $m$ уравнения Периса сравнивались с параметрами $m$, полученными стандартным способом на плоских образцах на внецентренное растяжение. Выявлены различия величины параметров Периса для образцов, испытанных при высоких значениях температуры. Полученная информация позволит спрогнозировать живучесть и кинетику роста трещины для деталей, изготовленных из данного материала, и работающих в условиях, соответствующих МЦУ, и при температуре, достигающей $750{ }^{\circ} \mathrm{C}$.

Ключевые слова: растровый электронный микроскоп, малоцикловая усталость, численное моделирование роста трещины, скорость роста усталостной трещины, гранулируемый никелевый сплав, ЭП741НП, живучесть, период зарождения трещины.
\end{abstract}

\author{
M.A. Artamonov ${ }^{1}$, D.V. Nemtsev ${ }^{1}$, V.E. Medentsov ${ }^{2}$, V.S. Solovyev ${ }^{2}$ \\ ${ }^{1}$ A. Lyulka Design Bureau PJSC "UEC-Ufa Engine Industrial Association” Subsidiary, \\ Moscow, Russian Federation \\ ${ }^{2}$ Lytcarino Engineering Plant affiliate PJSC "UEC-Ufa Engine Industrial Association", \\ Moscow, Russian Federation
}

\title{
ANALISYS OF CYLINDRICAL SPECIMENS OF NI-BASED SUPERALLOY EP741NP TESTED ON LOW CYCLE FATIGUE TO DETERMINE PARAMETERS PARIS AND DURATION OF INITIATION CRACK
}

\begin{abstract}
Using a scanning electron microscope, an information on initiation and propagation kinetics of fatigue cracks in powder Ni-based superalloy EP741NP was obtained. This alloy is used for the GTE disks manufacturing. The testing of the cylindrical specimens at the low cycle fatigue (LCF) was carried out in a wide range of temperatures from 20 to $750{ }^{\circ} \mathrm{C}$ under strain control (fixed strain amplitude). The results of the fractographic analysis of fracture surfaces of the specimens made it possible to determine the place of initiation fatigue crack, duration of crack growth and duration of initiation crack for different temperatures. The dependence of duration of initiation crack on temperature was found. Specific fraction of the initiation crack in the total durability of the specimen is constant and occupies more than $50 \%$ at temperature up to $450{ }^{\circ} \mathrm{C}$. The shape and dimensions of the crack for each specimen were determined. They were used for finite element modeling to determine the coefficient of Paris law that characterize the kinetics of the fatigue stage II. The obtained values of the coefficient of Paris law were compared with the similar coefficient obtained on standard compact-tension (CT) specimen for fatigue crack growth rate testing. Differences in
\end{abstract}


the values of the coefficient of Paris law were found for specimens tested by high temperature. The obtained information will allow to predict the duration of initiation crack and duration of crack growth of the parts from this superalloy in the conditions of the corresponding LCF and at temperature up to $750{ }^{\circ} \mathrm{C}$.

Keywords: scanning electron microscope, low-cycle fatigue, numerical modeling of crack growth, rate growth of fatigue crack, powder nickel-base superalloy, EP741NP, crack growth duration, duration of initiation crack.

\section{Введение}

Для изготовления дисков турбины современных газотурбинных двигателей (ГТД) и энергетических установок (ГТУ) часто используют гранулируемые жаропрочные никелевые сплавы $[1,2]$. Максимальные рабочие значения температуры деталей, изготовленных из данных материалов, достигают $650^{\circ} \mathrm{C}$ и выше. В случае возникновения в детали трещины, с учетом условий работы (уровень напряжений, режим нагружения, температура), наиболее вероятно разрушение по механизму малоцикловой усталости (МЦУ). Ввиду этого особенно важно знать усталостные характеристики материала и то, какие факторы могут оказать влияние на развитие разрушения в материале. Усталостную характеристику материала оценивают зависимостью между долговечностью (количество циклов до разрушения материала) и размахом напряжения или деформации [3, 4]. Вместе с тем любой процесс усталостного разрушения проходит в два этапа: зарождение усталостной трещины (определяется через количество циклов, требующихся на зарождение трещины) и рост трещины, определяемый живучестью (количеством циклов развития трещины в детали до ее долома). Механизмы этих процессов различны, и поэтому необходимо отдельно исследовать влияние на зарождение и рост усталостной трещины таких параметров, как температура, асимметрия цикла, состояние структуры материала.

Знание живучести позволит, в свою очередь, определить и назначить такую важную характеристику, обеспечивающую экономичную и безопасную эксплуатацию изделия, как межремонтный ресурс.

По заказу ОКБ им. А. Люльки в Лыткаринском машиностроительном заводе (ЛМЗ) были изготовлены цилиндрические образцы из сплава ЭП741НП и проведены испытания на МЦУ. Испытание образцов проводилось с использованием испытательной машины серии 8862 фирмы Instron в широком диапазоне значений температуры - от 20 до $750{ }^{\circ} \mathrm{C}$. После проведения испытаний на МЦУ был проведен фрактографический анализ изломов разрушенных образцов. Фрактографическое исследование проводилось с использованием растрового электронного микроскопа JSM-IT300LV фирмы JEOL. Целью данного исследования было определение кинетики развития усталостного разрушения в образцах, что позволило выявить реализованную живучесть образцов. Знание живучести и долговечности позволило, в свою очередь, определить период зарождения усталостной трещины в материале.

Динамика развития усталостной трещины характеризуется параметрами Периса $C$ и $m$, относящимися к зависимости между скоростью роста усталостной трещины $d a l d N$ и размахом коэффициента интенсивности напряжения (КИН) $\Delta K$ для второй, устойчивой стадии развития усталостной трещины [5, 6]:

$$
d a / d N=C \Delta K^{m}
$$

Также на живучесть образца влияют такие параметры, как критический КИН (циклическая вязкость разрушения) $K_{\mathrm{fc}}$ и пороговый коэффициент интенсивности напряжения $K_{\mathrm{th}}$. Данные параметры зависят от температуры, при которой происходило усталостное разрушение материала.

\section{Исследуемый материал и тип образцов}

Материал образцов - никелевый гранулируемый сплав ЭП741НП. Размер гранул сплава, из которого были изготовлены образцы, не превышает 140 мкм [7]. Образцы были вырезаны из диска турбины высокого давления (ТВД). Микроструктура сплава после термической обработ- 
ки представляет собой твердый раствор $\gamma-\mathrm{Ni}$ со средним размером зерна 40 мкм, по границам зерен присутствуют крупные частицы упрочняющей интерметаллидной $\gamma^{\prime}$-фазы размером до 3 мкм. Заготовки под образцы вырезаны из ступицы ТВД в осевом направлении.

Для испытания применялись цилиндрические образцы. Диаметр и длина рабочей части равны соответственно 4,37 и 13 мм.

Поверхность образцов была отшлифована с последующей полировкой в осевом направлении для исключения образования поперечных рисок вдоль окружности образца. Подобная схема полирования позволила исключить зарождение усталостных трещин от рисок, оставшихся после механической обработки.

\section{Методика проведения исследования}

До начала испытаний измерялся модуль Юнга при комнатной температуре и температуре испытания $T=350,450,550,650$ и $750{ }^{\circ} \mathrm{C}$. Время выдержки системы с установленным образцом до начала испытания после достижения заданной температуры составляло 1 ч.

Испытания на МЦУ проводились в соответствии с ГОСТ 25.502-79 при «жестком» цикле нагружения. Параметры нагружения при испытаниях образцов: форма цикла - синусоидальная; частота нагружения - 1 Гц; контролируемый параметр в процессе нагружения - размах деформации в цикле $\Delta \varepsilon=1 ;$ коэффициент асимметрии цикла $R_{\varepsilon}=\left(\varepsilon_{\text {мин }} / \varepsilon_{\text {макс }}\right)=0$.

Параметры нагружения постоянные в процессе испытаний (с момента нагружения до момента разрушения образца). Разрушением образца при испытании на МЦУ считалось разделение образца на части либо снижение максимальной нагрузки в цикле на $25 \%$ по сравнению с величиной нагрузки в первом цикле. Такое снижение нагрузки свидетельствует о появлении макротрещины в образце, после чего компьютерная программа выдает команду о прекращении испытания.

В ходе фрактографического исследования полученного излома устанавливалось местонахождение очагов и тип усталостного разрушения образца. В случае нахождения нескольких очагов для последующего анализа выбирался тот очаг, которому принадлежала наибольшая область усталостного разрушения. Фиксировались координаты очага. Производился поиск участков, на которых можно наблюдать формирование усталостных бороздок. Данные участки должны располагаться вдоль одной прямой и соответствовать вектору развития усталостной трещины от очага. Для каждого локального участка излома фиксировались координаты и проводилось измерение шага усталостных бороздок (размер которых характеризует скорость роста усталостной трещины за один цикл нагружения). Шаг усталостной бороздки определялся путем измерения блока усталостных бороздок и усреднения по количеству усталостных бороздок, находящихся в данном блоке. Полученная зависимость скорости роста усталостной трещины от расстояния до очага позволяет подсчитать количество циклов развития трещины (живучесть Np) [8].

Принимается, что скорость роста усталостной трещины от очага до первого локального участка излома, на котором наблюдается формирование усталостных бороздок, характеризуется размером шага усталостных бороздок, измеренных на этом участке. В реальности можно ожидать, что скорость роста усталостной трещины между очагом и первым локальным участком ниже, а значит, и количество циклов больше. Данная разница между вычисленным и реальным количеством циклов будет отнесена к периоду зарождения усталостной трещины.

Период зарождения усталостной трещины получается из следующего соотношения:

$$
N_{o}=N_{f}-N_{p}
$$

где $N_{f}$ - общая долговечность образца, $N_{o}$ - период зарождения усталостной трещины.

Отношение периода роста трещины к общей долговечности образца:

$$
t=N_{p} / N_{f} .
$$


По излому определялась форма усталостной трещины на начальном и конечном участках роста усталостной трещины.

\section{Методика проведения расчетов}

Целью проведения расчета является получение зависимостей размаха коэффициента интенсивности напряжений $\Delta K$ от размеров трещины для каждого исследуемого образца. Моделирование образца с трещиной выполнялось в программном комплексе ANSYS [9].

Модель для конечно-элементного анализа представлена на рис. 1. При моделировании учитывались: температура проведения испытаний, величина относительных деформаций образца, геометрические размеры трещины в точках анализа усталостных бороздок. Нагрузка моделировалась условием перемещения, соответствующим деформациям при проведении испытаний в жестком цикле нагружения.

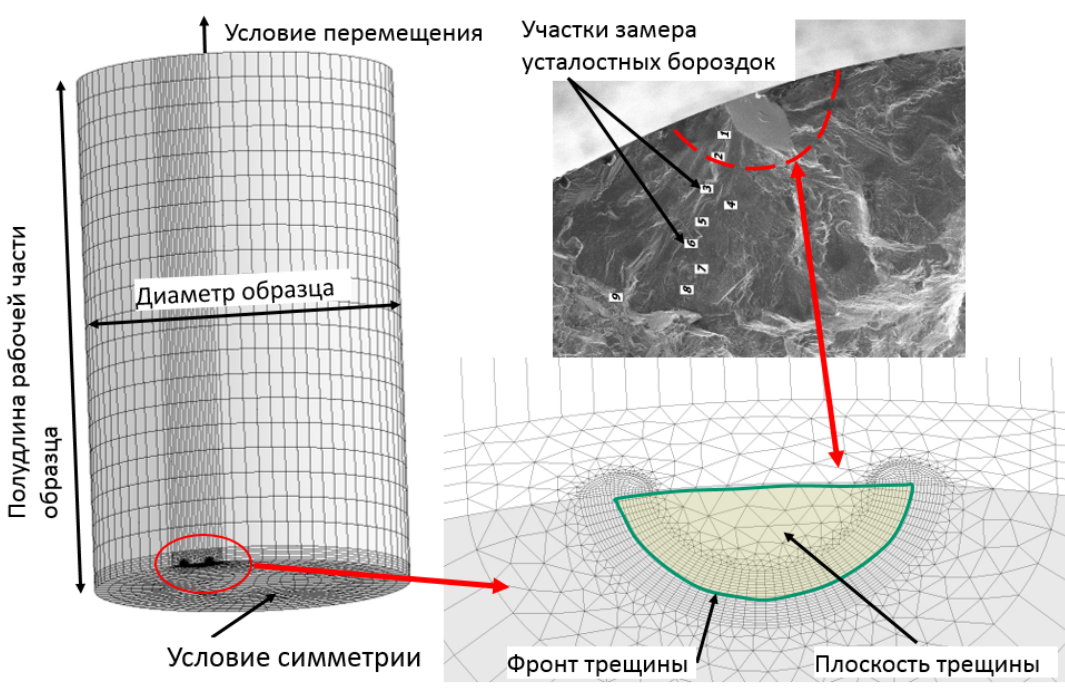

Рис. 1. Конечно-элементная модель трещины в образце

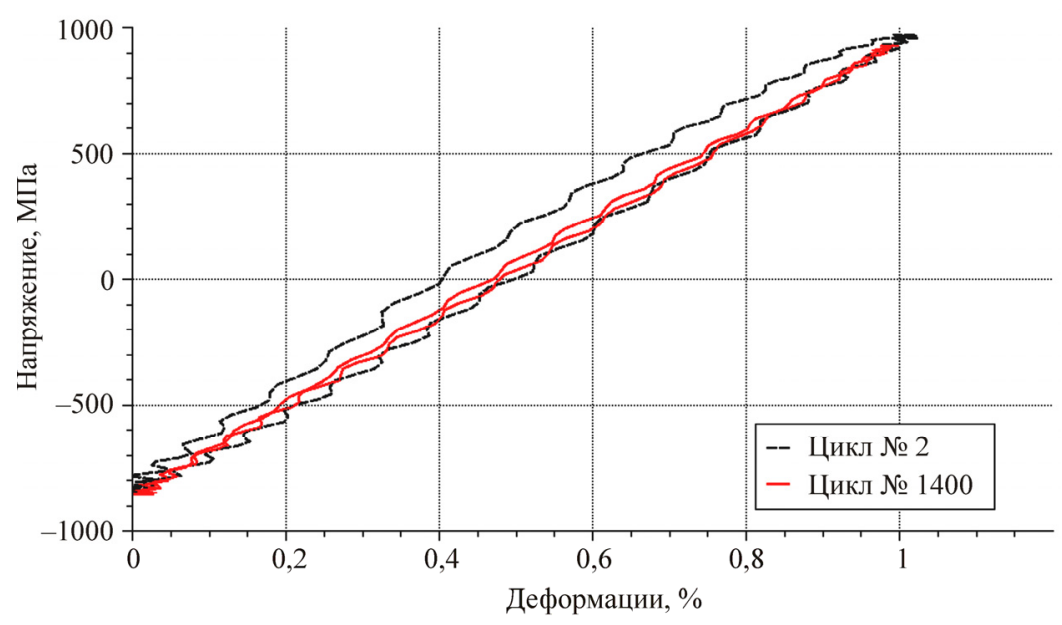

Рис. 2. Петли гистерезиса для цилиндрического образца при $550{ }^{\circ} \mathrm{C}$

Расчет выполнялся в упругой постановке с индивидуальным значением модуля Юнга для каждого образца. Модуль Юнга получен после обработки петель гистерезиса, записанных при испытании каждого образца. На рис. 2 представлены петли гистерезиса, полученные при испы- 
тании образца при $550{ }^{\circ} \mathrm{C}$, соответствующие циклу начала испытания (цикл № 2) и циклу начала роста трещины (цикл № 1400). Из представленного графика видно, что при цикле № 1400 происходит «схлопывание» петли гистерезиса и материал, получив упрочнение, работает в условиях упругого напряженно-деформированного состояния. Однако при температуре $20^{\circ} \mathrm{C}$ «схлопывания» диаграммы нагружения не происходит, размах пластических деформаций сохраняется на всех циклах испытаний образцов. Ввиду этого получение значений $m$ и $C$ формулы (1) для образцов, испытанных при температуре $20^{\circ} \mathrm{C}$, данным методом некорректно.

Распределение КИН по фронту трещины (рис. 3) определялось встроенной функцией CINT через Ј-интеграл для плоского деформированного состояния. Значение КИН на фронте бралось в местах исследования усталостных бороздок (см. рис. 1 - места обозначены цифрами на поверхности излома). Затем строилась зависимость полученных значений размахов КИН от глубины (рис. 4).

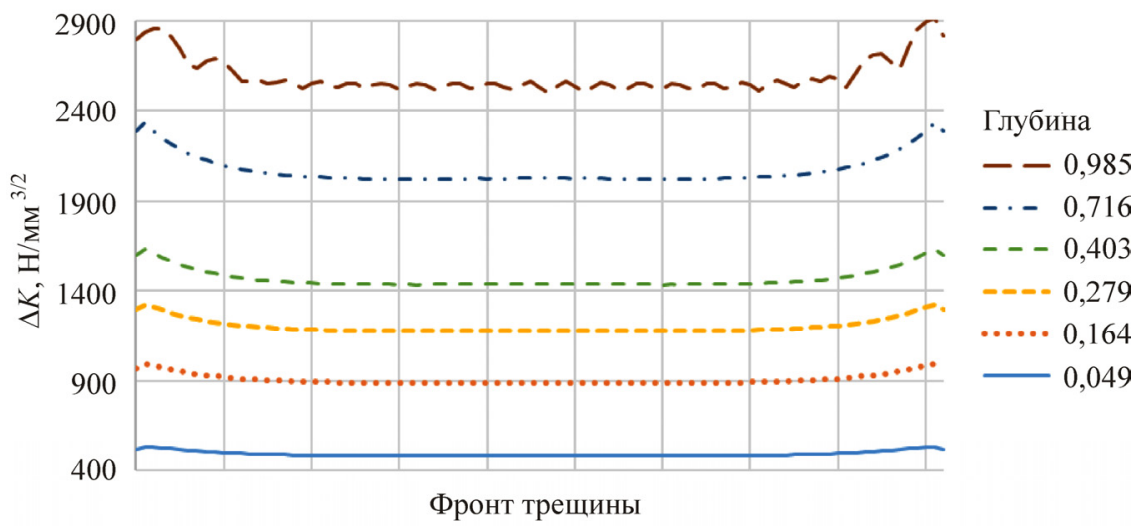

Рис. 3. Распределение КИН по фронту трещины для различных размеров трещины

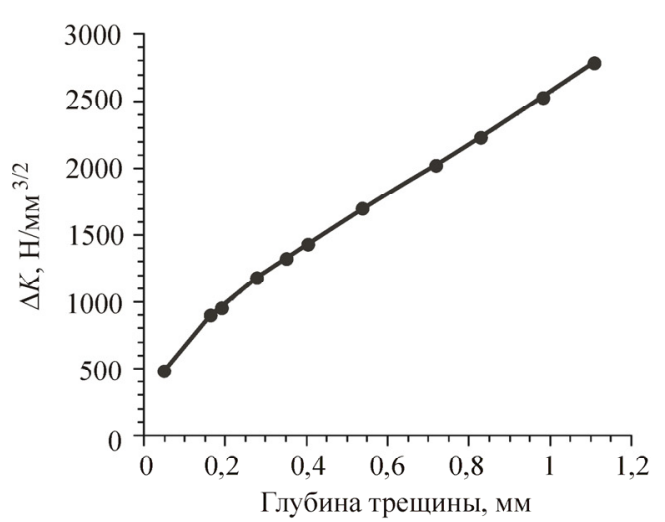

Рис. 4. Размах КИН от глубины трещины

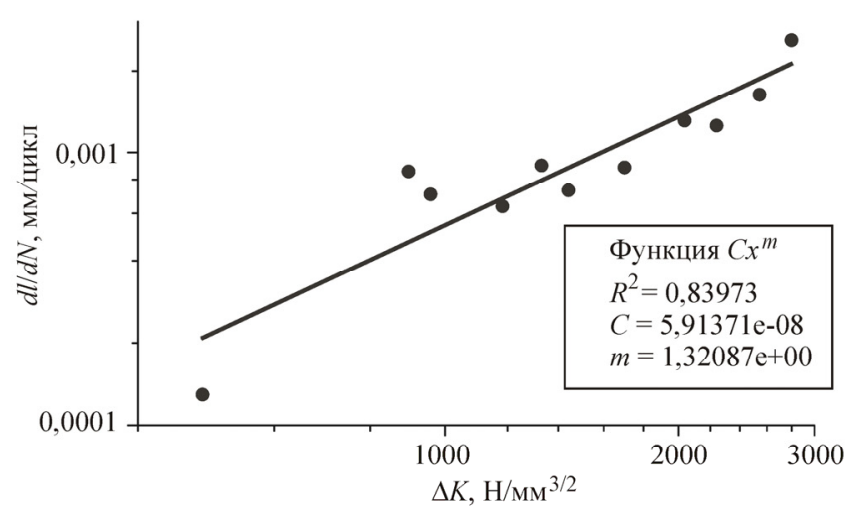

Рис. 5. Кинетическая диаграмма роста трещины в цилиндрическом образце

Для каждого образца в логарифмических осях строились зависимости скорости роста трещины усталости, полученные методами фрактографии, от величины размаха КИН [10, 11]. Для примера на рис. 5 приведена данная зависимость, полученная для образца, испытанного при температуре $650{ }^{\circ} \mathrm{C}$. Аппроксимацией данных зависимостей уравнением Периса (1) были получены коэффициенты $C$ и $m$ для каждого цилиндрического образца.

При фрактографическом исследовании наблюдалось многоочаговое зарождение усталостных трещин, при этом расчет выполнялся для модели, содержащей одну трещину с наибольшей областью усталостного разрушения. Для определения влияния на результаты расчета наличия дополнительных трещин был проведен расчет модели с двумя и четырьмя одинаковыми 
трещинами, равномерно расположенными по поверхности образца. Расхождение в значениях КИН для модели с двумя трещинами, по сравнению с моделью с одной трещиной, составило $1 \%$, расхождение в результатах расчета при использовании модели с четырьмя трещинами, по сравнению с моделью с одной трещиной, составило $6 \%$.

\section{Результаты проведенного исследования}

Полученные значения долговечности образцов, испытанных на МЦУ, показаны на рис. 6. Можно отметить относительно высокий разброс величин и ожидаемое снижение долговечности с ростом температуры.

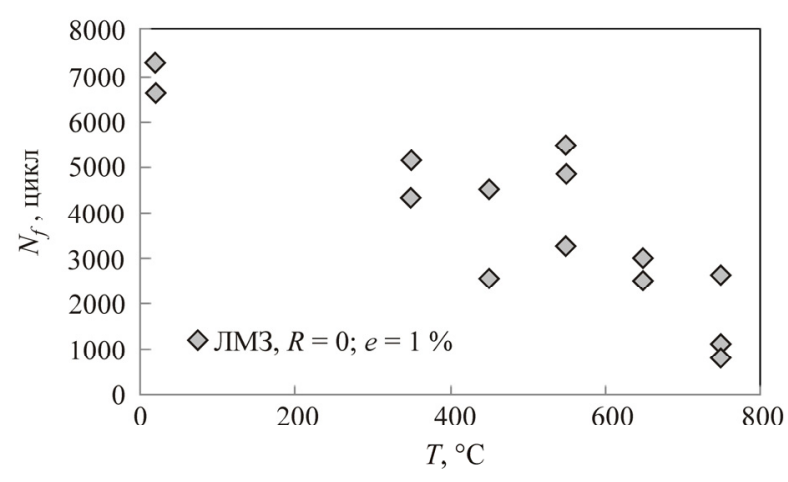

Рис. 6. Зависимости долговечности от температуры

Был проведен фрактографический анализ изломов, полученных при испытаниях на МЦУ. Для всех образцов наблюдается многоочаговое зарождение усталостных трещин, при этом очаговые области для всех исследуемых образцов находятся на боковых поверхностях образцов (рис. 7).

В очаге усталостного зарождения трещины часто наблюдается фасетка, ограниченная размерами аустенитного зерна и развернутая по отношению к оси нагружения (см. рис. 7, б). Фасетки выходят на боковую поверхность образцов. Как правило, фокус очага находится на поверхности, но иногда он расположен на определенном расстоянии от поверхности.

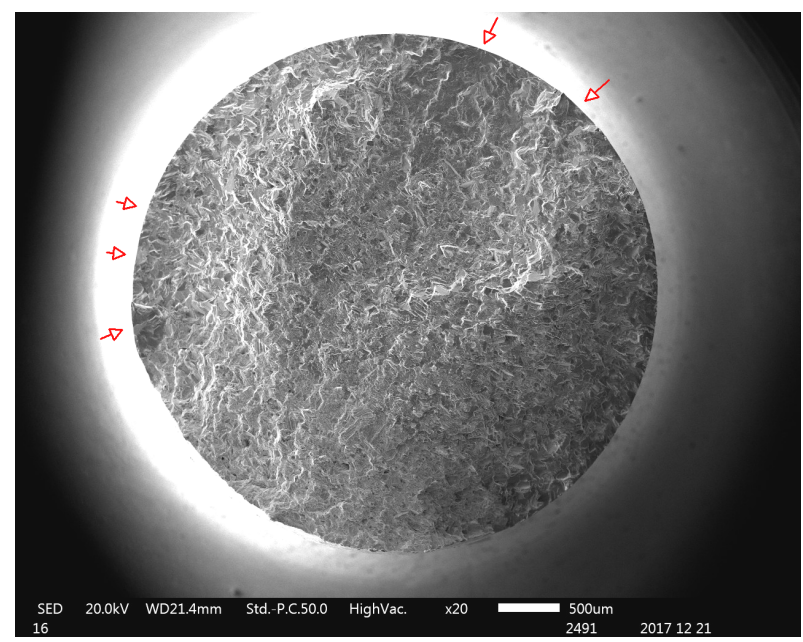

$a$

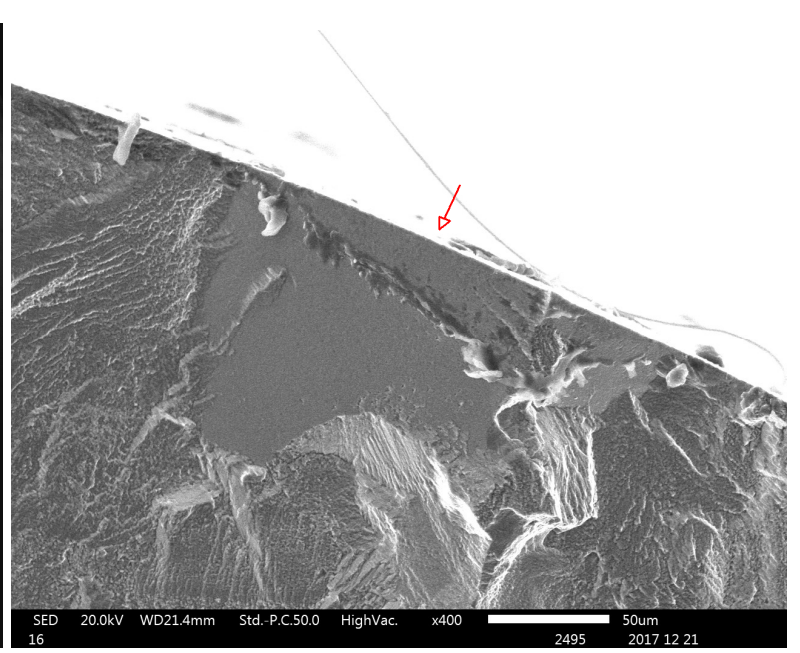

$\sigma$

Рис. 7. Микростроение излома образца, испытанного при $550{ }^{\circ} \mathrm{C}: a-$ общий вид излома; $\sigma$ - поверхность образца у очаговой зоны. Расположение очагов усталостных трещин показано стрелками. В очаговой области наблюдается фасетка (б)

Дальнейшее распространение трещины происходит с формированием усталостных бороздок (рис. 8).

Измерение шага усталостных бороздок на локальных участках излома позволило получить картину роста усталостной трещины. На рис. 9 показан пример зависимости скорости роста трещины от расстояния до очага для образца, испытанного при температуре $550{ }^{\circ} \mathrm{C}$. В peзультате проведения расчета конечно-элементной модели образца с внедренной трещиной получены величины размахов КИН, которые были сопоставлены со скоростью роста трещины, 
полученной измерением шага усталостных бороздок. Это позволило определить показатели Периса (см. рис. 5).

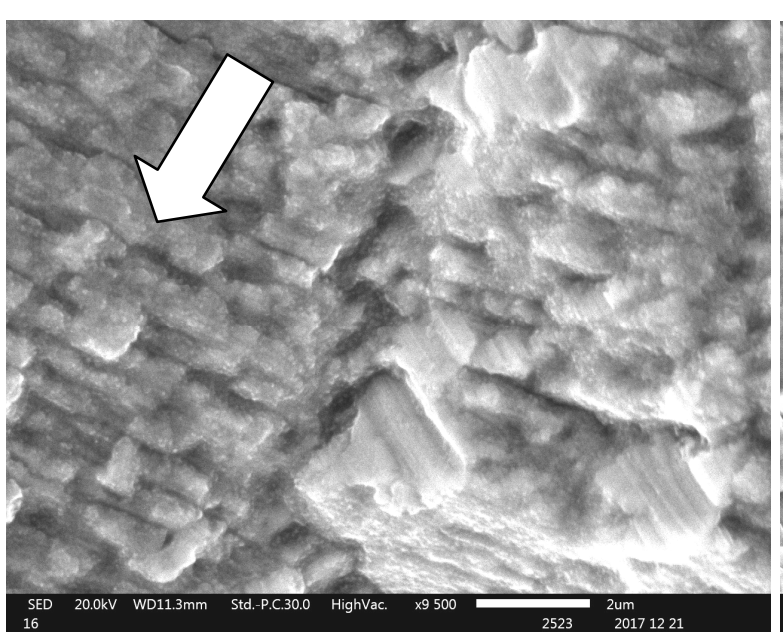

$a$

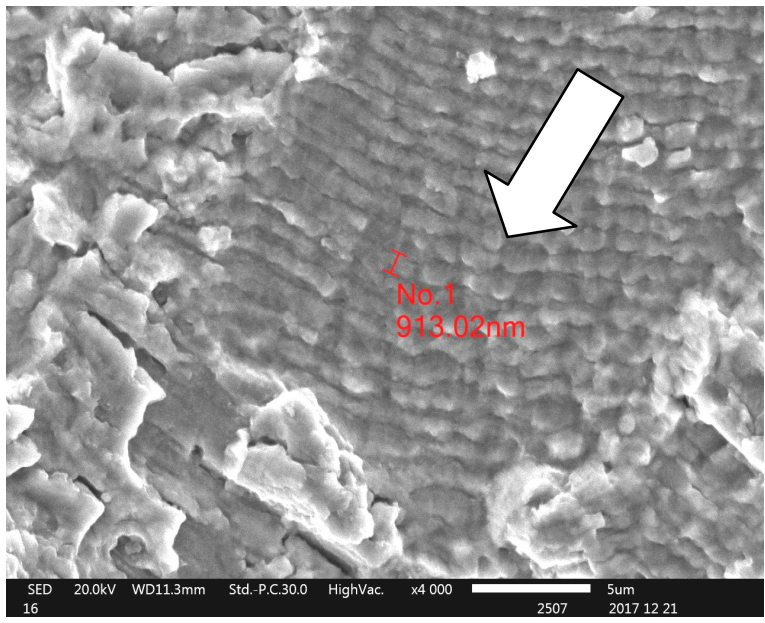

6

Рис. 8. Локальные участки излома, на которых наблюдается формирование усталостных бороздок на начальной стадии роста трещины (средний размер шага бороздок $\approx 0,136$ мкм) (a) и на заключительной стадии ( $\approx 0,9$ мкм) (б). Направление развития разрушения показано стрелками

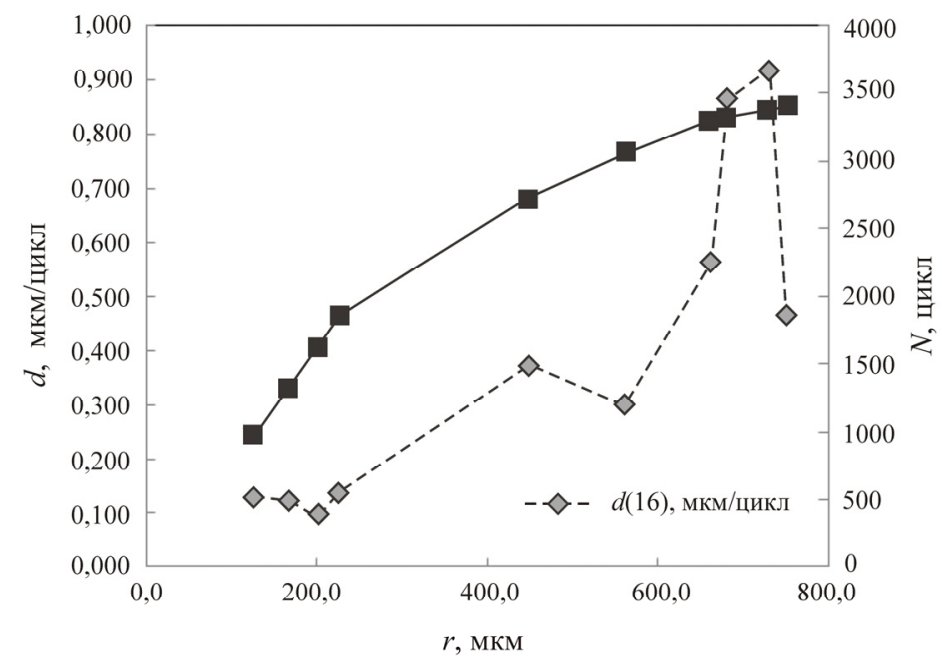

Рис. 9. Зависимость скорости роста усталостной трещины и приращения циклов от расстояния до очага для образца, испытанного при температуре $550{ }^{\circ} \mathrm{C}$

После проведения подобного анализа для всех исследуемых образцов были получены значения показателей Периса $m$ и $C$ (рис. 10). Известно [12], что показатель Периса $m$ для данного сплава линейно зависит от температуры. Однако при больших значениях температуры наблюдается отклонение в значениях показателя $m$, полученных при испытаниях цилиндрических образцов и плоских образцов на внецентренное растяжение (BP $)^{1}$. Значения коэффициентов Периса при испытаниях образцов типа ВР были получены в ходе исследования, проведенного по заказу ОКБ им. А. Люльки.

${ }^{1}$ ASTM international. ASTM Standard E1820-13: standard test method for measurement of fatigue crack growth rates / West Conshohocken, PA, ASTM International. 2000. 


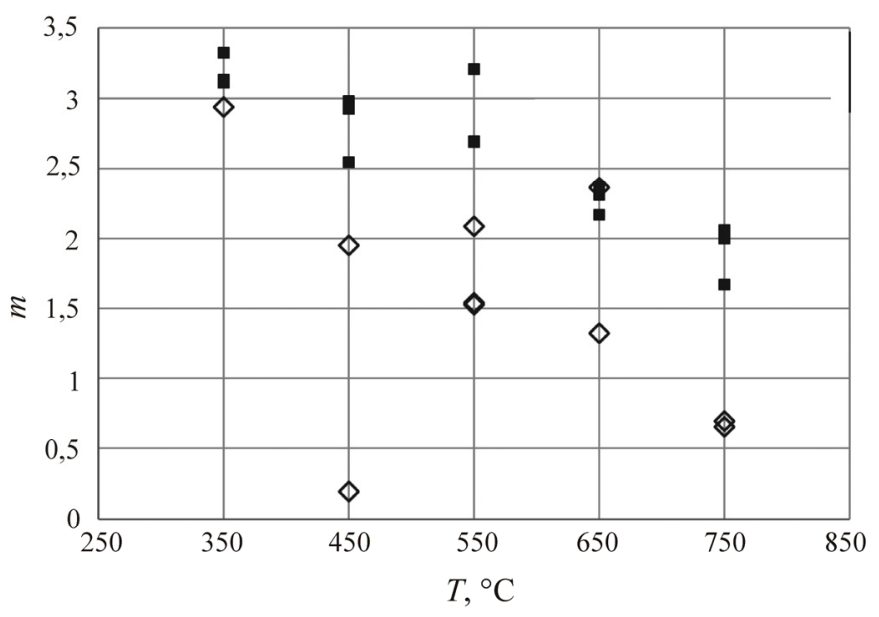

Рис. 10. Зависимость коэффициента $m$ от температуры для цилиндрических образцов и для образцов типа ВР: $\diamond$ цилиндрические образцы; $\mathbf{\square}$ образцы ВР

Возможно, данное различие в характеристике скорости роста трещины связано с влиянием двух факторов. Для цилиндрических образцов форма усталостных трещин близка к эллиптическому виду, в то время как для образцов типа ВР фронт усталостной трещины линейный [13]. Вторым фактором является разный механизм усталостного разрушения при испытаниях: для цилиндрических образцов - испытание по МЦУ, для плоских образцов типа ВР, как правило, проводят испытания по МнЦУ (многоцикловая усталость), при котором материал не испытывает нагрузку, превышающую предел текучести. Величина размаха КИН во время роста трещины в цилиндрическом образце и образце типа ВР может быть одинаковой, однако цилиндрический образец начинает испытывать пластические деформации уже в первом цикле нагружения и при распространении усталостной трещины в материале его свойства могут отличаться от исходного.

На рис. 10 наблюдается сильное отклонение от основной зависимости для одного образца, испытанного при температуре $450{ }^{\circ} \mathrm{C}$. Для данного образца наблюдается аномальное снижение скорости роста трещины от расстояния до очага. Такое поведение может быть связано с наличием трещин, находящихся в том же секторе, но в другом сечении образца. Взаимное влияние этих трещин могло привести к падению напряжений при развитии трещин.

Определение зависимости скорости роста трещины от расстояния до очага позволило оценить длительность развития разрушения и, следовательно, рассчитать живучесть образцов. Полученные результаты оценки живучести образцов и величины $t$, соответствующей отношению живучести образца к долговечности (2), показаны на рис. 11.

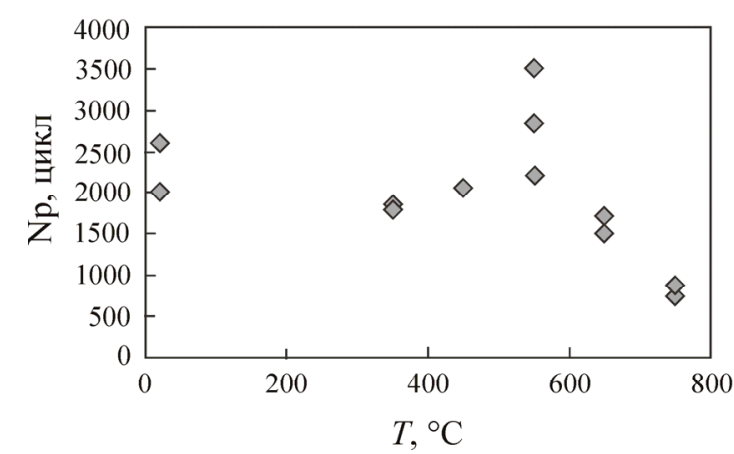

$a$

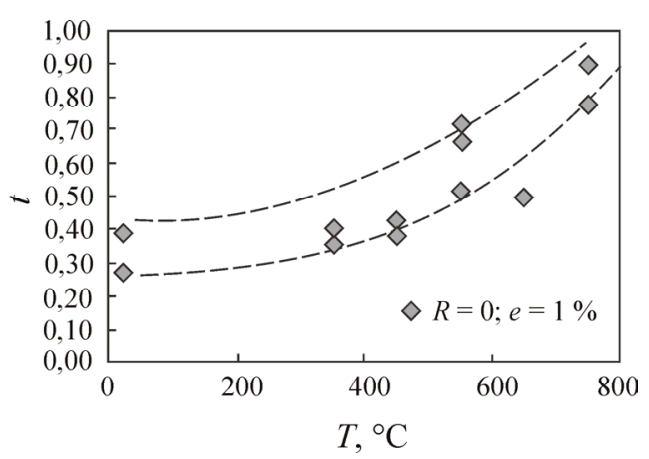

$\sigma$

Рис. 11. Зависимости живучести (a) и показателя $t$ (живучести к долговечности) (б) от температуры 
Разброс характеристик живучести значительно меньше, чем разброс полученных результатов оценки долговечности (см. рис. 6 и рис. 11, $a$ ). Это объясняется исключением влияния на живучесть такого фактора, как зарождение усталостной трещины, который оказывает значительное влияние на результат оценки долговечности. Для данного материала наблюдается характерная особенность - при изменении температуры от 20 до $550{ }^{\circ} \mathrm{C}$ живучесть образцов не уменьшается, а даже наблюдается ее небольшой рост. При дальнейшем увеличении температуры происходит резкое падение живучести образцов (см. рис. 8). Для объяснения данного феномена можно отметить, что на результат оценки живучести оказывают влияние не только скорость роста трещины, но и длительность стабильного роста усталостной трещины. Повышение температуры при этом увеличивает пластичность материала и, можно ожидать, задерживает переход от устойчивого роста трещины к ускоренному росту.

Наблюдается приращение значения величины $t$ с ростом температуры (см. рис. $8, \sigma$ ). Высокая долговечность образцов при испытании с низкой температурой обеспечивается длительностью периода зарождения усталостной трещины. Повышение рабочей температуры приводит к ускорению движения дислокаций в материале, усилению воздействия окружающей среды (кислорода) на материал и снижению остаточных сжимающих напряжений, существующих в приповерхностных слоях материала [14]. Все это приводит к существенному снижению времени зарождения усталостной трещины.

Температура оказывает влияние на рост усталостной трещины. Зависимость показателя Периса $m$ в исследованном диапазоне значений температуры близка к линейной (см. рис. 10). Сочетание параметров роста усталостной трещины с изменением величины размаха КИН, характеризующего переход от устойчивого к неустойчивому росту трещины $(\Delta K 23)$, приводит к сложной зависимости живучести (количества циклов роста трещины) от температуры (см. рис. $8, a$ ).

\section{Выводы}

Полученное исследование показало наличие особенностей изменения живучести образцов, изготовленных из никелевого материала ЭП741НП, в зависимости от температуры. В диапазоне значений температуры от 20 до $550{ }^{\circ} \mathrm{C}$ живучесть не снижается. При более высоких значениях температуры происходит резкое уменьшение живучести.

С ростом температуры наблюдается увеличение параметра $t$, являющегося отношением периода развития трещины к общей долговечности (2). Высокая долговечность образцов в процессе испытания при относительно низкой температуре обеспечивается длительностью периода зарождения усталостной трещины.

Температура оказывает влияние на динамику роста усталостной трещины. Полученные результаты показывают линейную зависимость показателя уравнения Периса $m$ от температуры в исследуемом диапазоне значений температуры.

При высоких значениях температуры значение коэффициента $m$ уравнения Периса, полученного при испытаниях цилиндрических образцов, отличается от значений коэффициента, полученного при испытаниях образцов типа ВР.

\section{Библиографический список}

1. Применение дисков из гранул жаропрочных никелевых сплавов в серийных ГТД авиационной и наземной техники / А.А. Иноземцев, Н.Ф. Аношкин, И.Г. Башкатов, Г.С. Гарибов, А.С. Коряковцев // Перспективные технологии легких и специальных сплавов. - М.: Физматлит, 2006. - С. 371-376.

2. Симс Ч.Т., Норман С.С., Уильям С.Х. Суперсплавы II. Жаропрочные материалы для аэрокосмических и промышленных энергоустановок. - М.: Металлургия, 1995. - Т. 1. - 384 с.

3. Estimation of fatigue parameters in total strain life equation for powder metallurgy superalloy FGH96 and other metallic materials / Y. Wang, X. Wang, B. Zhong, D. Wei, X. Jiang // Inter. J. of Fatigue 123. - 2019. P. 66-78. DOI: https://doi.org/10.1016/j.ijfatigue.2019.01.007 
4. A study of low cycle fatigue life and its correlation with microstructural parameters in IN713C nickel based superalloy / J. Salvat Canto, S. Winwood, K. Rhodes, S. Birosca // Material Sci. and Eng. A. - 2018. Vol. 718. - P. 19-32. DOI: https://doi.org/10.1016/j.msea.2018.01.083

5. Шанявский А.А. Безопасное усталостное разрушение элементов авиаконструкций. Синергетика в инженерных приложениях. - Уфа: Монография, 2003. - 803 с.

6. Партон В.3., Морозов Е.М. Механика упругопластического разрушения. - М.: Наука, 1974. $504 \mathrm{c}$.

7. The influence of temperature-strain rate conditions on hot workability and microstructure of powder metallurgy nickel-based superalloy EP741NP / A. Ganeev, V. Valitov, F. Utyashev, V. Imayev // IOP Conf. Series: Materials Sci. and Eng. - 2018. - No. 447. - P. 6. DOI: 10.1088/1757-899X/447/1/012062

8. Исследование влияния температуры на усталостные характеристики гранулируемого никелевого сплава ЭП741НП / М.А. Артамонов, Д.В. Немцев, В.Э. Меденцов, В.С. Соловьев // Климовские чтения - 2018. Перспективные направления развития авиадвигателестроения: сб. докл. науч.-техн. конф. СПб., 2018. - С. 144-152.

9. Морозов E.M. ANSYS в руках инженера. Механика разрушения. - М.: Ленанд, 2010. - 456 с.

10. Кинетика и продолжительность роста усталостных трещин в сталях при переменном нагружении / А.Н. Савкин, Р. Сундер, К.А. Бадиков, А.А. Седов // Вестник Пермского национального исследовательского политехнического универститета. Механика. - 2018. - № 3. - C. 61-70. DOI: 10.15593/perm.mech/2018.3.07

11. Numerical simulations of cracked round bar test: Effect of residual stresses and crack asymmetry / J. Poduska, P. Hutar, A. Frank, J. Kucera, J. Sadilek // Eng. Fracture Mech. - 2018. - No. 203. - P. 18-31. DOI: https://doi.org/10.1016/j.engfracmech.2018.06.032

12. Потапов С.Д., Перепелица Д.Д. Исследование циклической скорости роста трещин в материалах основных деталей авиационных ГТД // Технология легких сплавов. - 2013. - № 2. - С. 5-19.

13. Потапов С.Д., Перепелица Д.Д. Исследование влияния геометрических особенностей трещины на характеристики циклической трещиностойкости // Технология легких сплавов. - 2014. - № 1. - С. 66-71.

14. Судзуки Т. Динамика дислокаций и пластичность. - М.: Мир, 1989. - 296 с.

\section{References}

1. Inozemtsev A.A., Anoshkin N.F., Bashkatov I.G., Garibov G.S., Koryakovtsev A.S. Primeneniye diskov iz granul zharoprochnykh nikelevykh splavov v seriynykh GTD aviatsionnoy i nazemnoy tekhniki [Application of disks from heat-resistant Ni-based alloys in serial GTE of aviation and ground equipment]. Perspektivnyye tekhnologii legkikh i spetsialnykh splavov. Moscow, FIZMATLIT, 2006, pp. 371-376.

2. Sims C.T., Norman S.S., William C.H. Supersplavy II. Zharoprochnyye materialy dlya aerokosmicheskikh i promyshlennykh energoustanovok [Heat-resistant materials for aerospace and industrial power plants]. Moscow: Metallurgiya, vol. 1, 1995, 384 p.

3. Wang, Y., Wang, X., Zhong, B., Wei, D., Jiang, X. Estimation of fatigue parameters in total strain life equation for powder metallurgy superalloy FGH96 and other metallic materials. International Journal of Fatigue 123, 2019, pp. 66-78. DOI: https://doi.org/10.1016/j.ijfatigue.2019.01.007

4. Salvat Canto J., Winwood S., Rhodes K., Birosca S. A study of low cycle fatigue life and its correlation with microstructural parameters in IN713C nickel based superalloy. Material Science and Engineering A., 2018, vol. 718, pp. 19-32. DOI: https://doi.org/10.1016/j.msea.2018.01.083

5. Shanyavskiy A.A. Bezopasnoye ustalostnoye razrusheniye elementov aviakonstruktsiy. Sinergetika $\mathrm{v}$ inzhenernykh prilozheniyakh [Tolerance fatigue failures of aircraft components]. Ufa, Monografiya, 2003, $803 \mathrm{p}$.

6. Parton V.Z., Morozov E.M. Mekhanika uprugo-plasticheskogo razrusheniya [Mechanics of elasticplastic fracture]. Moscow, Nauka, 1974, 504 p.

7. Ganeev A., Valitov V., Utyashev F., Imayev V. The influence of temperature-strain rate conditions on hot workability and microstructure of powder metallurgy nickel-based superalloy EP741NP. IOP Conf. Series: Materials Science and Engineering, 2018, no. 447, 6 p. DOI: 10.1088/1757-899X/447/1/012062

8. Artamonov M.A., Nemtsev D.V., Medentsov V.E., Solov'yev V.S. Issledovaniye vliyaniya temperatury na ustalostnyye kharakteristiki granuliruyemogo nikelevogo splava EP741NP [Investigation of influence of temperature on the fatigue characteristics of Ni-based alloy EP741NP]. Proceedings of the scientific 
and technical conference "Klimovskiye chteniya - 2018. Perspektivnyye napravleniya razvitiya aviadvigatelestroyeniya”. Saint-Petersburg, 2018, pp.144-152.

9. Morozov E.M. ANSYS v rukakh inzhenera. Mekhanika razrusheniya [ANSYS in the hands of an engineer. Fracture mechanics]. Moscow, Lenand, 2010, 456 p.

10. Savkin A.N., Sunder R., Badikov K.A., Sedov A.A. Fatigue crack growth kinetic on stell under variable amplitude loading. PNRPU Mechanics Bulletin, 2018, no. 3, pp. 61-70. DOI: 10.15593/perm.mech/2018.3.07

11. Poduska J., Hutar P., Frank A., Kucera J., Sadilek J. Numerical simulations of cracked round bar test: Effect of residual stresses and crack asymmetry. Engineering Fracture Mechanics, 2018, no. 203(2018), pp. 18-31. DOI: https://doi.org/10.1016/j.engfracmech.2018.06.032

12. Potapov S.D., Perepelitsa D.D. Issledovanie tsiklicheskoy skorosti rosta treshchin $\mathrm{v}$ materialakh osnovnykh detaley aviatsionnykh GTD [Tests for cyclic crack growth rate in materials of critical aircraft gasturbine engine components]. Tekhnologiya legkikh splavov, 2013, no. 2, pp. 5-19.

13. Potapov S.D., Perepelitsa D.D. Issledovanie vliyaniya geometricheskikh osobennostey treshchiny na kharakteristiki tsiklicheskoy treshchinostoykosti [Investigation of the effect of geometrical features of cracks on cyclic crack resistance characteristics]. Tekhnologiya legkikh splavov, 2014, no. 1, pp. 66-71.

14. Sudzuki T. Dinamika dislokatsiy i plastichnost [Dislocation dynamics and plasticity]. Moscow, Mir, 1989,296 p.

\section{Об авторах}

Артамонов Максим Анатольевич (Москва, Россия) - кандидат физико-математических наук, начальник бригады отдела прочности опытно-конструкторского бюро им. А. Люльки - филиала ПАО «ОДК-УМПО» (129301, г. Москва, ул. Касаткина, д. 13, e-mail: maxartamonov @ gmail.com).

Немцев Дмитрий Владимирович (Москва, Россия) - инженер-конструктор 1-й категории отдела прочности опытно-конструкторского бюро им. А. Люльки - филиала ПАО «ОДК-УМПО» (129301, г. Москва, ул. Касаткина, д. 13, e-mail: dmitrij_n@inbox.ru).

Меденцов Виктор Эдуардович (г. Лыткарино, Московская обл., Россия) - ведущий инженерметалловед Лыткаринского машиностроительного завода - филиала ПАО «ОДК-УМПО» (140080, Московская обл., г. Лыткарино, промзона Тураево, стр. 9, e-mail: medentsovve@ gmail.com).

Соловьев Валерий Сергеевич (г. Лыткарино, Московская обл., Россия) - инженер-технолог Лыткаринского машиностроительного завода - филиала ПАО «ОДК-УМПО» (140080, Московская обл., г. Лыткарино, промзона Тураево, стр. 9, e-mail: Jinto14@ yandex.ru).

\section{About the authors}

Maxim A. Artamonov (Moscow, Russian Federation) - CSc in Physical and Mathematical Scirnces, Head of the Brigade, Strength Department, A. Lyulka Design Bureau PJSC "UEC-Ufa Engine Industrial Association" Subsidiary (13, Kasatkina st., Moscow, 129301, Russian Federation, e-mail: maxartamonov@gmail.com).

Dmitriy V. Nemtsev (Moscow, Russian Federation) - Design Engineer of the first Category, Strength Department, A. Lyulka Design Bureau PJSC "UEC-Ufa Engine Industrial Association" Subsidiary (13, Kasatkina st., Moscow, 129301, Russian Federation, e-mail: dmitrij_n@inbox.ru).

Victor E. Medentsov (Lytcarino, Moscow region, Russian Federation) - Lead Metal Engineer, Lytcarino Engineering Plant affiliate "UEC-Ufa Engine Industrial Association PJSC" (9, Turaevo industrial zone, Lytcarino, Moscow region, 140080, Russian Federation, e-mail: medentsovve@gmail.com).

Valery S. Solovyev (Lytcarino, Moscow region, Russian Federation) - Process Engineer, Lytcarino Engineering Plant affiliate "UEC-Ufa Engine Industrial Association PJSC" (9, Turaevo industrial zone, Lytcarino, Moscow region, 140080, Russian Federation, e-mail: Jinto14@yandex.ru).

Получено 19.03.2019 